\title{
Microstructural Studies of Thermal Spray Coating
}

\author{
Chennupati Vijaya Kumar \\ SSIT, \\ Sathupally-Khammam , \\ India
}

\author{
Subhash Kamal, PhD \\ Universiti Teknologi Petronas, \\ Malaysia
}

\begin{abstract}
Chromium carbide nickel chrome, $\mathrm{Cr}_{3} \mathrm{C}_{2}-\mathrm{NiCr}$ coatings applied on AISI 340 alloy steel through high velocity oxy-fuel (HVOF). In this microstructural studies, steel sample were prepared to differentiate the thickness of the coating based on the hardness value between coating and substrate. The experimental procedures $\mathrm{Cr}_{3} \mathrm{C}_{2}-\mathrm{NiCr}$ thermal spray coating process, testing procedure and equipment involved were being determined through numbers of literature reviews and availability of equipment inside university laboratory. It is to prove that chromium carbide nickel chrome $\mathrm{Cr}_{3} \mathrm{C}_{2}-25 \mathrm{NiCr}$ can produce better protection for AISI 304 alloy steel.
\end{abstract}

\section{Keywords}

HVOF; Cr3C2-25NiCr; Vickers Microhardness; SEM; XRD

\section{INTRODUCTION}

$\mathrm{Cr} 3 \mathrm{C} 2-\mathrm{NiCr}$ is a chromium carbide nickel chrome coating which is used for coating powder for HVOF thermal spray coating. It been used due to high wear resistance and corrosion which can protect material for longer life span. Therefore, this studies conducted to know the microstructural of the chromium carbide coating which undergo HVOF thermal spray coating process in creating protecting layer for AISI 304 stainless steel substrate. Various coating technologies can be used in order to create protecting layer to create longer life span of material form environment. [1]Thermal spray coating is a process of separating the metallic or the nonmetallic materials which is stored in liquid or semi molten structure [2].The are many type of thermal process such as detonation ,ceramic rod, wire, high velocity oxy-fuel (HVOF) and plasma [2] . HVOF process, as illustrated in figure 1, utilizes a combination of oxygen, compressed air with various fuel gases such as hydrogen, propane, propylene, and even kerosene. Although the HVOF process uses the basic principle of combustion, the spray gun is designed differently than the standard oxy-fuel spray gun. The HVOF gun differences produce higher flame temperatures and higher velocities [1].

The HVOF process is used for coating purposes, because this process possesses high deposition efficiency, compared to the other thermal spray processes. The diffusion rate of the substrate elements to coating is smaller and the cost is lower than laser technique. Due to the higher velocity, relatively lower temperatures, and higher impact of the powder particles on the substrate material, the coatings with dense microstructure and less porosity are formed in HVOF process.

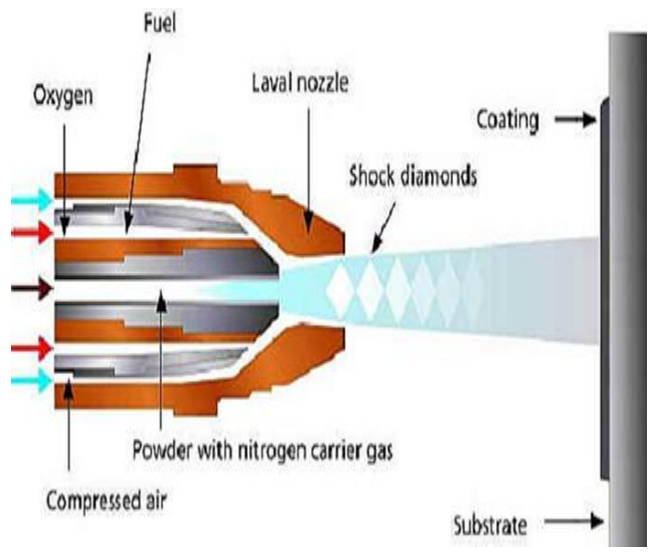

Figure 1: HVOF combustion spray [10]

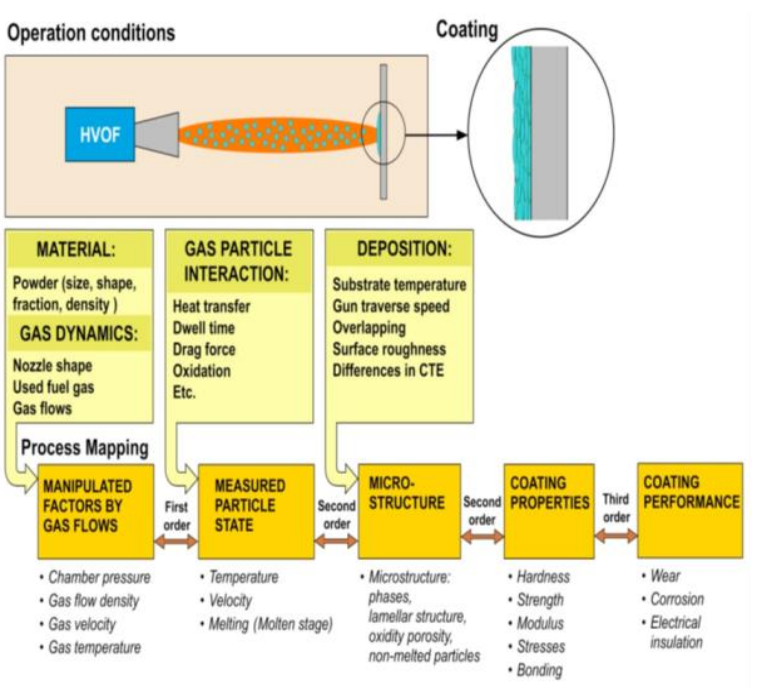

Figure 2: HVOF process [10]

temperatures up to $850^{\circ}$ [3]. $\mathrm{Cr} 3 \mathrm{C} 2$ carbide are refractory compound that combine many favorable properties such as for instance high hardness ,certain plasticity and good wettability with the bounding metal[4].Chromium carbide is utilized within blend with $\mathrm{Ni}-\mathrm{Cr}$ composite which enhances the durability and pliability of the coating [8].Therefor the combination of Chromium Carbide nickel chrome $\mathrm{Cr} 3 \mathrm{C} 2$ $25 \mathrm{NiCr}$ with $\mathrm{HVOF}$ process will create best structural characteristics compared to other type of thermal spray process $[3,20,23,25]$.In this paper, the focus will be towards themicrostructural studies when chromium carbide nickel chrome coating undergo the HVOF thermal spray process towards AISI 304 stainless steel. 


\section{METHODOLOGY}

\subsection{Preparation sample}

Preparation of cutting the material sample of austenitic stainless steel AISI $30450 \mathrm{~mm}$ diameter for 5 each sample. The substrates need to be cut to $50 \mathrm{~mm}$ diameter round shape to avoid any cracking during coating process

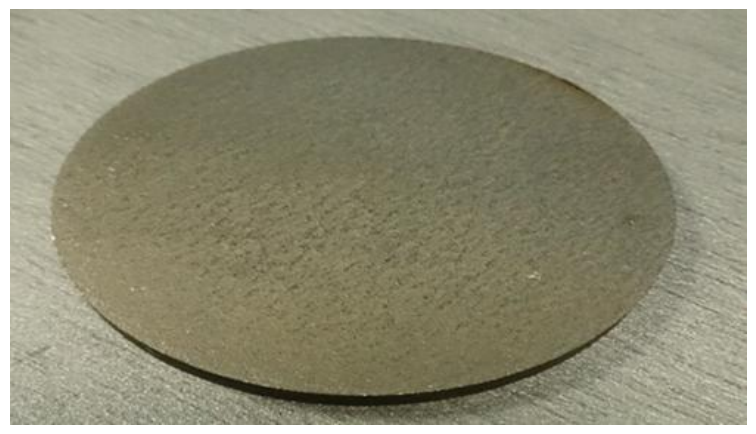

Figure 3: AISI 304 been cut and clean

All material on each page should fit within a rectangle of 1

In order to analyze the micro structural studies of thermal coating, specimen need to be prepared based on the parameters:

Table 1: Specimen parameters

\begin{tabular}{|c|c|}
\hline Parameters & Details \\
\hline Substrate & AISI 304 (stainless steel) \\
\hline Coating Powder & $\mathrm{Cr}_{3} \mathrm{C}_{2}-25 \mathrm{NiCr}$ \\
\hline Deposition Technique & $\mathrm{HVOF}$ \\
\hline Coating Thickness & $190 \mu \mathrm{m}$ \\
\hline
\end{tabular}

\subsection{HVOF coating spray process.}

The coating powder of $\mathrm{Cr} 3 \mathrm{C} 2-25 \mathrm{NiCr}$ need to be dry in an oven for 15 minutes with the temperature of $100^{\circ}$ c.Next sand blasting process will be done towards the sample substrate to create rough surface using high velocity in order for the coating to immerse with subtract during HVOF process. After sand blasting all the substrate, the coating machine need to be prepared. At the coating machine it has two part that is flow meter unit and powder meter unit. In flow meter unit it contain the parameters of fuel, oxygen and air pressure that will be used which the fuel that is $\mathrm{CH} 4$, oxygen and air will be supply toward the flow meter machine. Then it's the powder meter machine where the powder will placed in and an argon gas will supply towards the machine and transport the argon towards the coatinggun. Before undergo the HVOF process this is the parameter need to be set towards the flow meter and powder meter machine.
Table 2: HVOF spray parameters.

\begin{tabular}{|c|c|}
\hline Parameters & Details \\
\hline Fuel Gas & $\begin{array}{c}\mathrm{CH}_{4} \text { (Natural } \\
\text { Gas) }\end{array}$ \\
\hline Oxygen Pressure (bar) & 10.3 \\
\hline Fuel Pressure (bar) & 7.6 \\
\hline Air Pressure(bar) & 6.9 \\
\hline Oxygen Flow Rate, O $_{2}(\mathrm{NLPM})$ & 279 \\
\hline Fuel Flow Rate,CH & $(\mathrm{NLPM})$ \\
\hline Air Flow Rate, (NLPM) & 190 \\
\hline Argon Flow Rate (NLPM) & 361 \\
\hline Air Flow Rate, (NLPM) & 12.5 \\
\hline Spray Rate (g/min) & 361 \\
\hline Spray Distance (mm) & $38-75$ \\
\hline
\end{tabular}

After preparing the parameters needed to undergo the coating, HVOF process can be proceed. Firstly need to open up the flow meter allowing the natural gas, oxygen and air to flow towards the HVOF gun. Then start up the gun to create flair. Then turn on the powder meter machine allowing gas argon to flow with the coating powder towards the gun and create "Stun diamond" will be created leaving the spray gun .It will infused pivotally with extending high temperature gasses.

The coating process is done and the substrate cover with coating needed to be cold down based on room temperature.

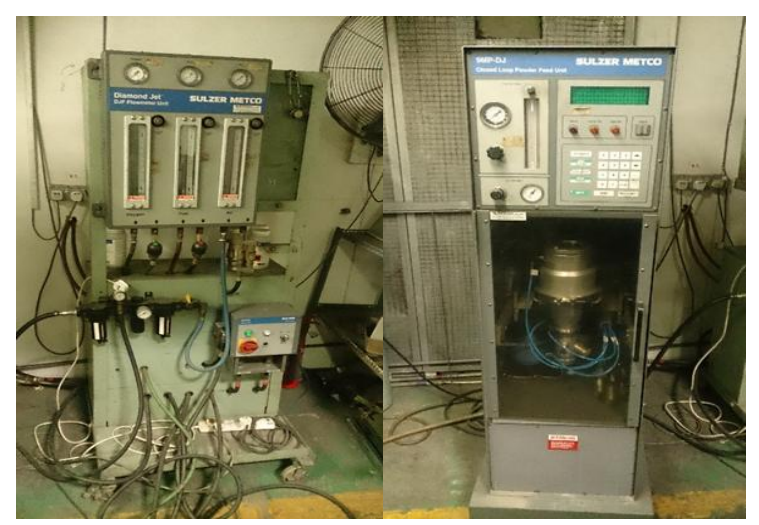

Figure 4: Flow and powder meter of HVOF machine

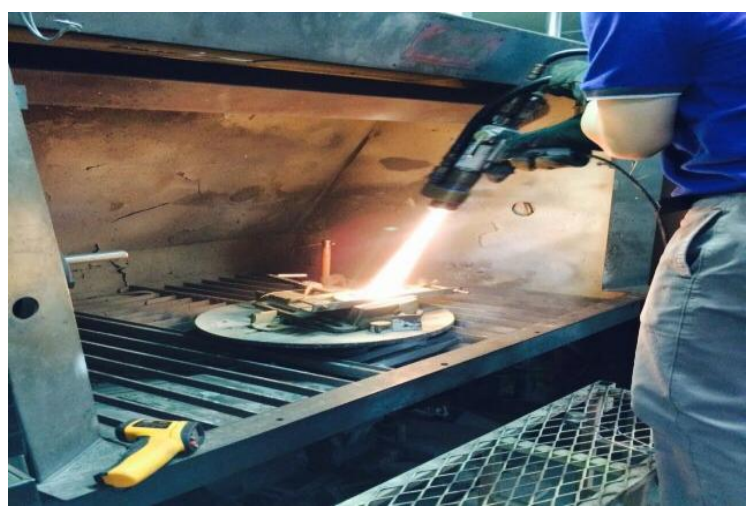

Figure 5: HVOF coating process 


\subsection{Vickers Microhardness Test}

This is the main test for the studies which determined how much the thickness of the coating. The test been done onto the coating at the cross section of the substrate AISI 304 based on ASTM E92. There are 6 deferent type of load were applied which are 50gf, 100gf, 200gf, 300gf, 500gf and 1000gf with 5 onwards vertical location at the cross section for 15 second.5 reading obtained based on the location with each loads.

\subsection{Microstructure and porosity}

The microstructure of the coatings was characterized by Scanning Electron Microscope (SEM) and its extension Energy Dispersive X-Ray Analysis (EDAX). Quantitative image analysis is done using ten SEM images at different position along the coating cross-section to estimate the average coating thickness and the porosity percentage of the coatings

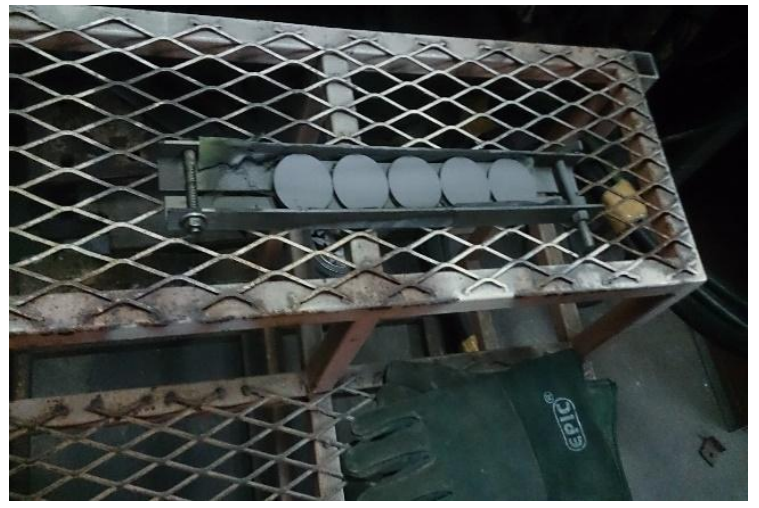

Figure 6: Coating Substrates

\subsection{X-Ray Powder Diffraction (XRD)}

It's a method that primary used in rapid analytical to indicate and identify crystalline of a material.

\section{RESULT \& DISCUSSION}

Table 3: Vickers Micro hardness Test

\begin{tabular}{|c|c|c|c|c|c|}
\hline Load & \multicolumn{5}{|c}{ Microhardness Reading (HV) } \\
\hline gf)/position & 1 & 2 & 3 & 4 & 5 \\
\hline 1000 & 409.9 & 326 & 313.7 & 301.2 & 273.2 \\
\hline 500 & 384.6 & 355.2 & 320.3 & 303 & 239 \\
\hline 300 & 418.3 & 373.8 & 288.3 & 275.2 & 279.6 \\
\hline 200 & 549.9 & 450.3 & 329.1 & 265.6 & 264.2 \\
\hline 100 & 462.7 & 451.3 & 320.6 & 281.9 & 281.2 \\
\hline 50 & 579 & 493.3 & 367.2 & 302.4 & 265.7 \\
\hline
\end{tabular}

In this result microhardness reading been taken across the cross section has been illustrated in figure 7 and microhardness reading were observed and shown on table 3 above. It is shown that based on the different position of the indentation of the diamond shape, the Vickers micro hardness test detect that the subtract cover with coating have high and subtract without coating have low indication of hardness value (HV). Using different load also indicated that using high loads can indicate low value of value when the diamond shape indentation will create large indication resulting low harness value (HV).Based on position, Position 1 indicated that it have highest hardness value (HV) reading as it was the coating covered on the top layer surface which are for $50 \mathrm{gf}$ is around $580 \mathrm{HV}$ and for $1000 \mathrm{gf}$ is around $400 \mathrm{gf}$. Then we can see decreasing value of hardness value (HV) from position 1 towards position 4 regardless what are the load been used. From position 4 to position 5 , it indicated that it is the substrate area where coating no longer exist which would have hardness value reading of 200-300 HV. Based on the result also, we can see load $1000 \mathrm{gf}$ have high reading compared to load 500gf and load 200gf also have high reading hardness value compared to load 100gf. This is due to inconsistency of the surface thickness profile along the coating surface which affected by the work of the sand blasting and the HVOF process towards the surface that cause this minor error.

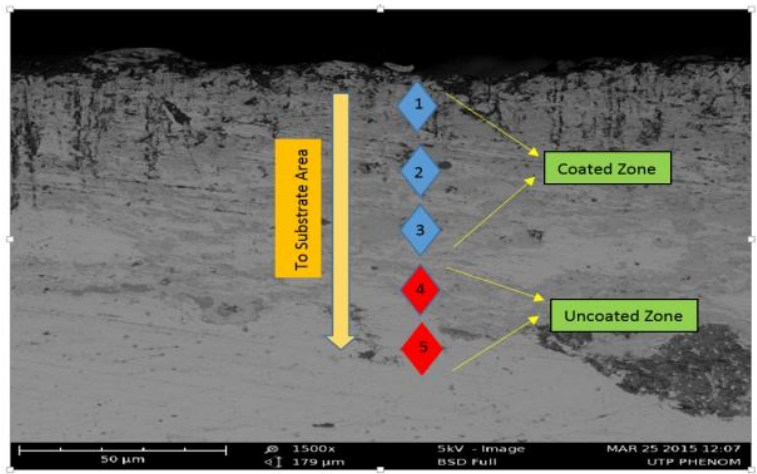

Figure 7: SEM microstructure view of positioning of indentation made across the coating cross section

e a 9-point text, as you see here. Please use sans-serif or non-

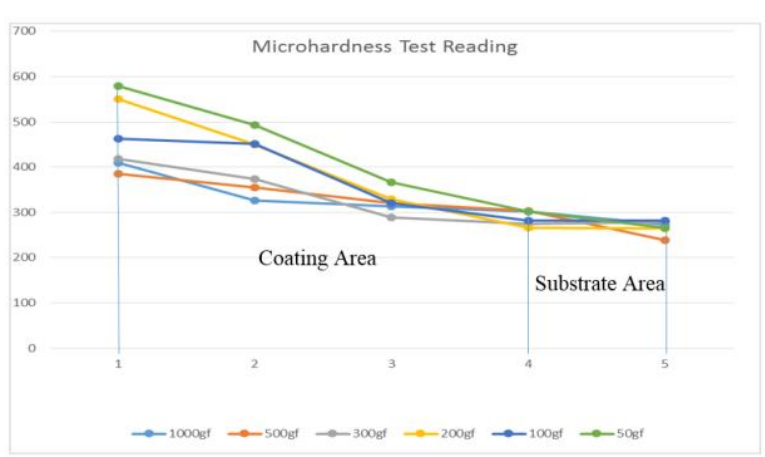

Figure 8: Vickers Mircro hardness Test

\subsection{Micro structure}

From figure above, the application of chromium carbide coating $\mathrm{Cr} 3 \mathrm{C} 2-25 \mathrm{NiCr}$ that been applied to AISI 304 stainless steel substrate through HVOF process will be creating an uniform, formed and dense protecting layer on top the surface substrate. Based on the coated microstructure surface view also "splats" can be detected while on the uncoated doesn't have. "Splat" occur during the HVOF process the chromium carbide coating $\mathrm{Cr} 3 \mathrm{C} 2-25 \mathrm{NiCr}$ when impacted towards the substrate revealing lamellar structure and solidify to another form continuous coating protective layer. The particle size of powder observed for this study respond to the other articles [24] and Ji et al [24].Based on extension Energy Dispersive 
X-Ray Analysis (EDAX), it shows the microstructure image mapping of the mix composition of element when chromium carbide nickel chrome coating mix with the substrate. In figure 12, it show the result of 5 chemicals composition that is carbon, oxygen, chromium, nickel and iron. Based on the SEM with EDAX also we can detect the difference between the uncoated and coated substrate based on the microstructural view figure 9 and figure 10 and the EDAX reading.

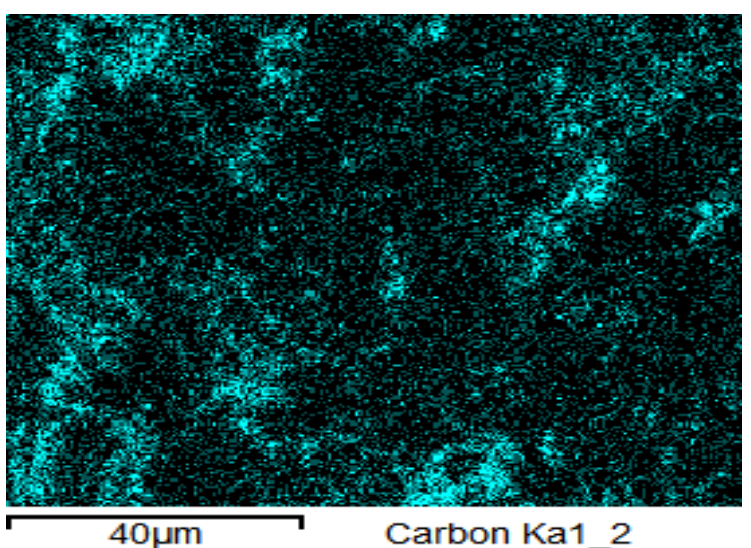

Figure 9: Uncoated microstructure surface 50 $\mu \mathrm{m}$

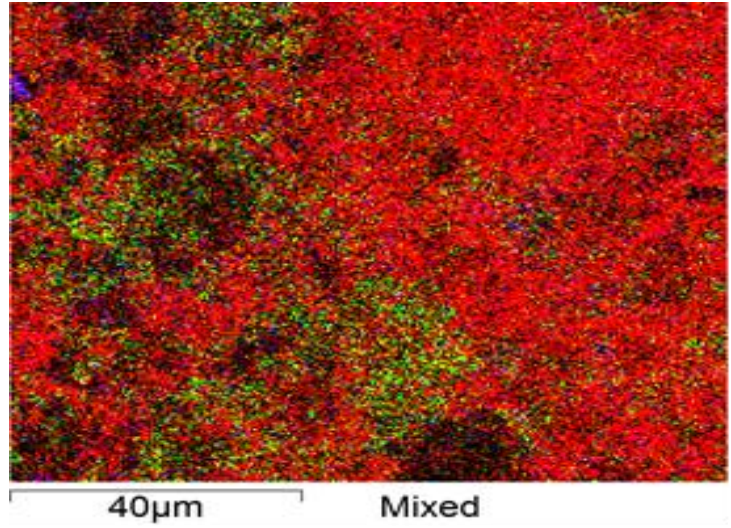

Figure 10: Coated microstructure surface 50 $\mu \mathrm{m}$ 


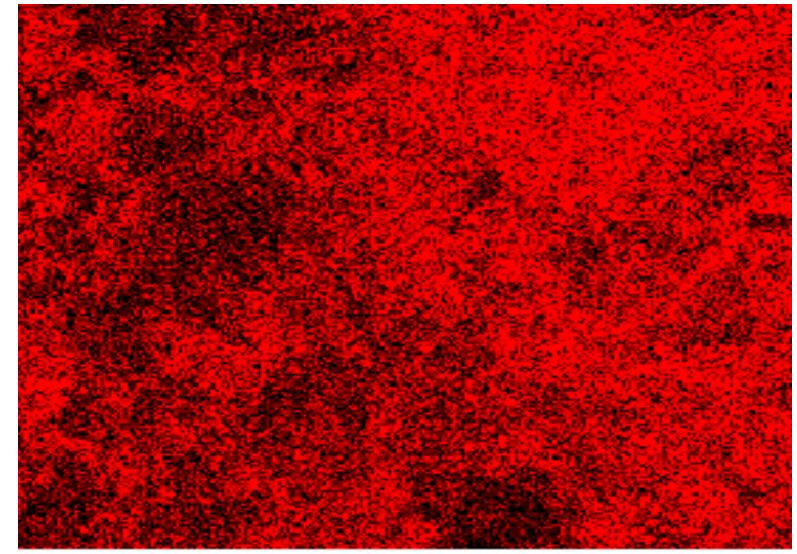

$40 \mu \mathrm{m}$ Chromium Ka1
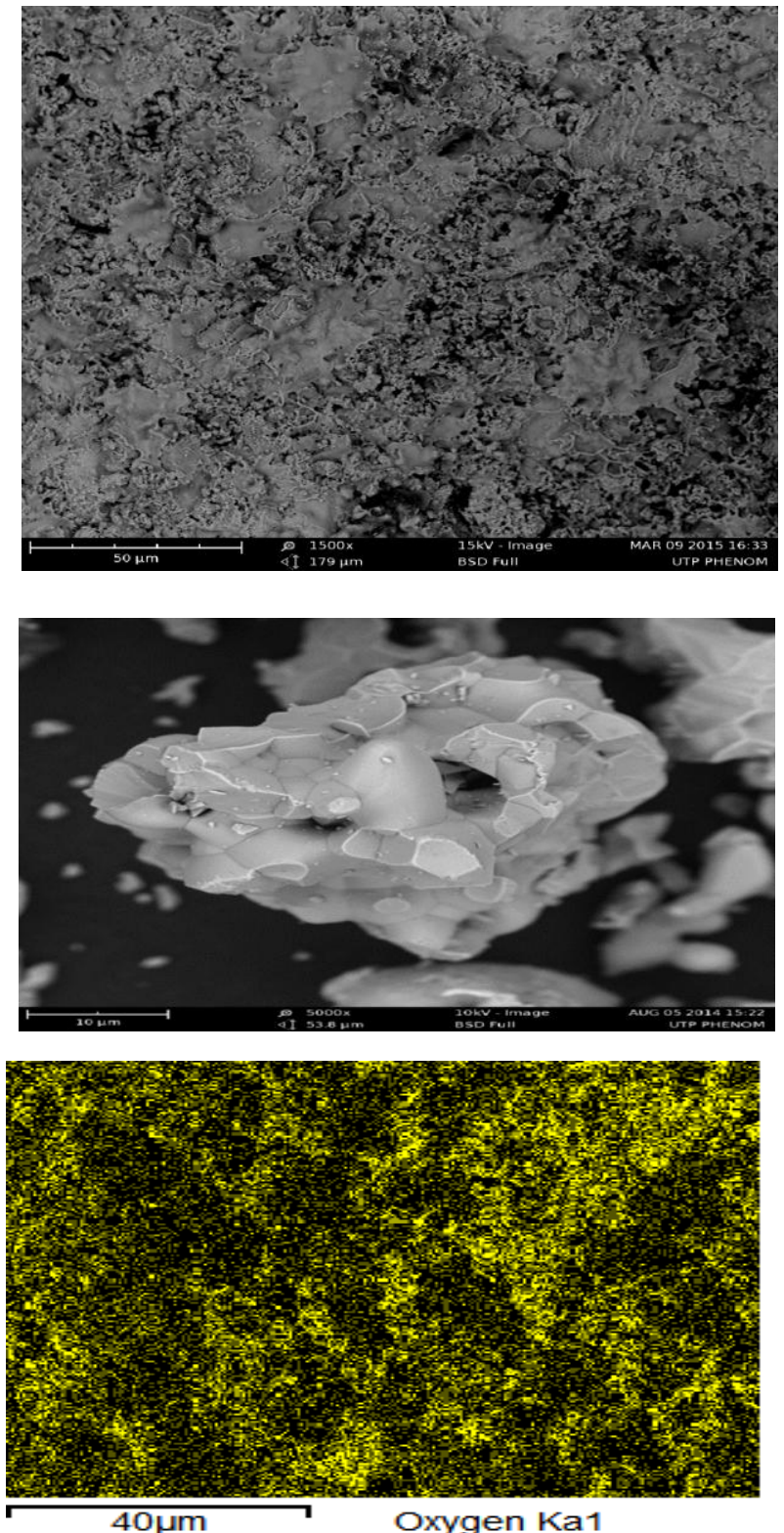

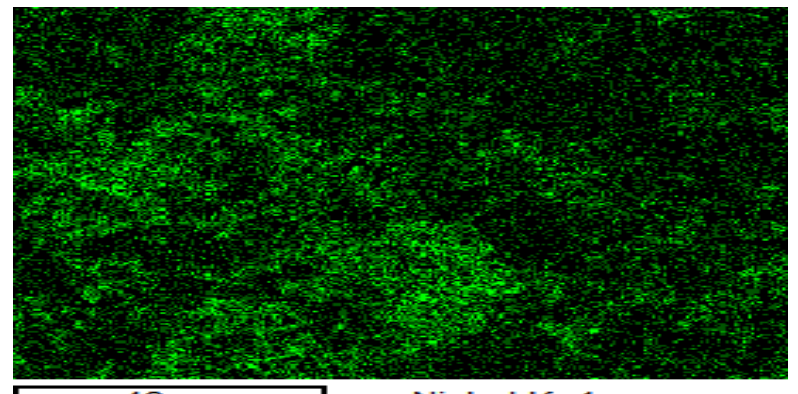

4OHm Nickel Ka1

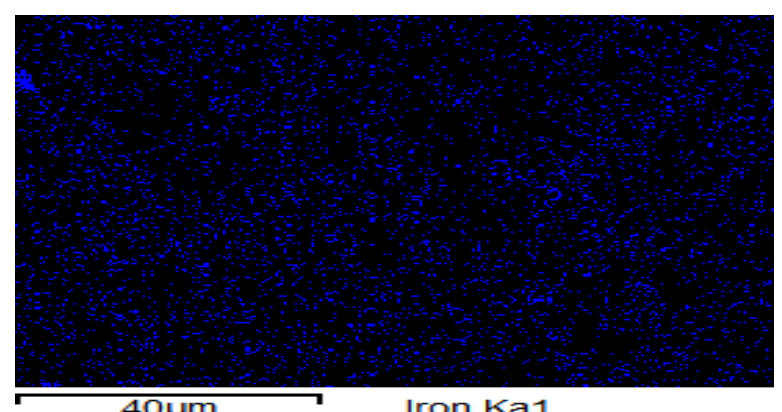

40um Iron Ka1

Figure 12: Element image mapping 


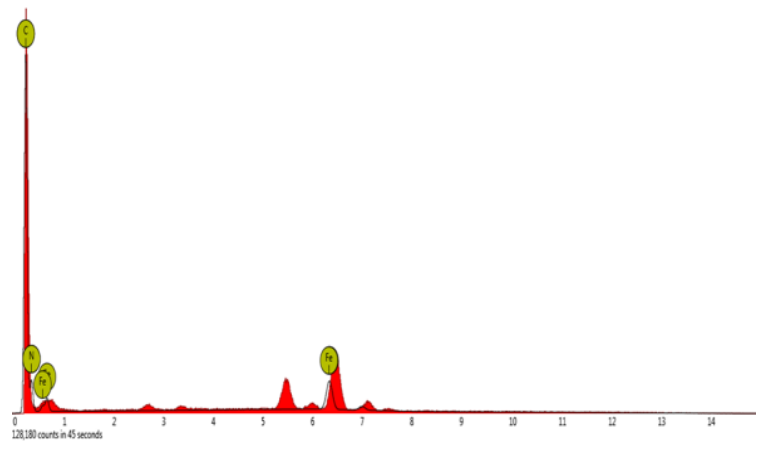

Figure 13: Uncoated substrate composition

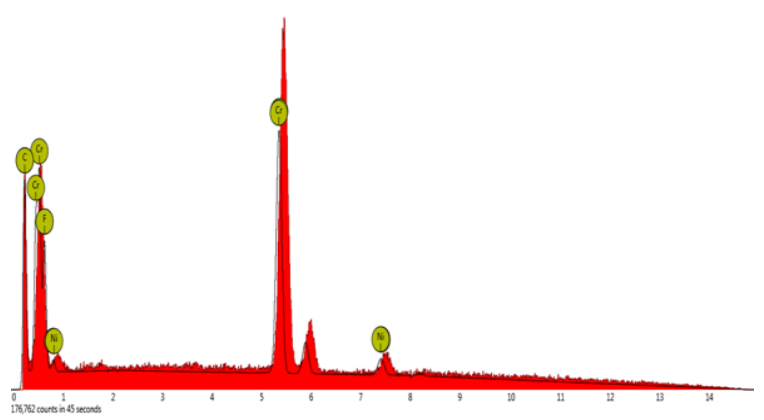

Figure 14: Coated substrate composition

Figure 13 and figure 14 above show the different between the composition of uncoated and coated substrate. Based on the reading before been coated carbon was the major composition. Then after the substrate was coated, chromium becomes the major composition follow by carbon, iron and nickel.

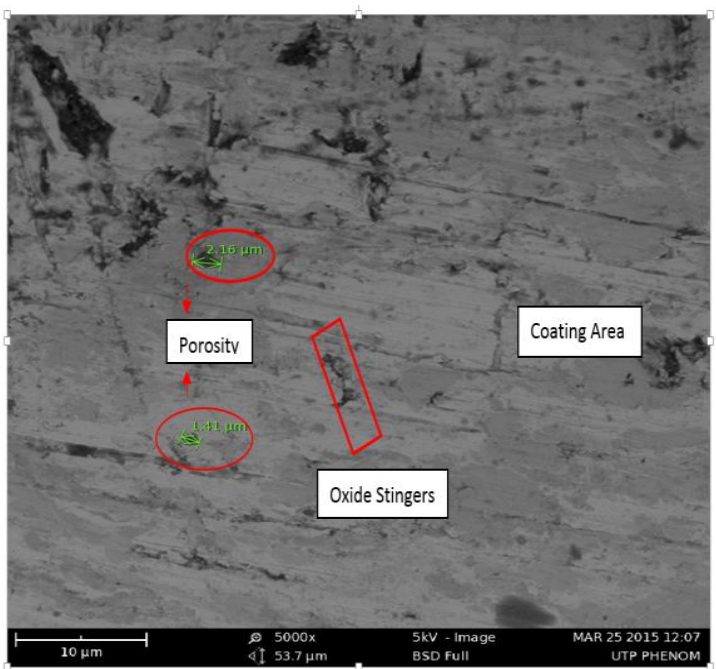

Figure 15: Cross Section view of coating obtained by SEM at 5000x magnification

process allow the coating to be dense and become better protective layer. In the coating also there also have the presence of oxide stringers this occur during the collect and harden of the coating compound after undergo the HVOF process. In this test, phased structured being analyzed by XRD and the finding can determine the characterization of crystalline material that's has within the coating. In this test, proves the coating chromium carbide nickel chrome have high reading of $\mathrm{Cr} 3 \mathrm{C} 2$ and $\mathrm{NiCr}$ lower. It shows that chromium carbide is the major and nickel chrome is the minor crystalline material and the combination both prove can create chromium carbide nickel chrome $\mathrm{Cr} 3 \mathrm{C} 2-25 \mathrm{NiCr}$ as a protective layer.

\section{CONCLUSION}

Based on the microstructural study been conducted, when undergo HVOF thermal spray process and used chromium carbide nickel chrome as the coating powder $\mathrm{Cr} 3 \mathrm{C} 2-25 \mathrm{NiCr}$ it can produce better protecting layer.This are the conclusion obtained based on the study:

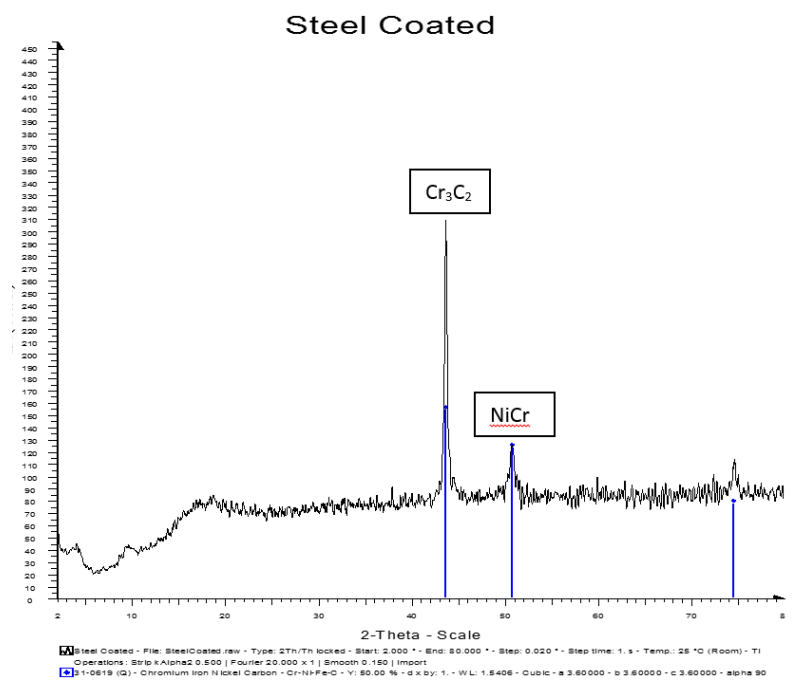

The vickers micro hardness test show that the $\mathrm{Cr} 3 \mathrm{C} 2 \mathrm{NiCr}$ coating have high value of hardness which mean the coating can be consider hardest and is valuable as protective shield. Using high load of $1000 \mathrm{gf}$ hardness value of the coating is about $400 \mathrm{HV}$ and using low load of $50 \mathrm{gf}$ the harness value is high 579HV.Here the difference of hardness value in not that far as the use of different load is huge and show the coating of chromium carbide using HVOF thermal spray process can produce hard protective coating.

HVOF thermal spray chromium carbide nickel chrome coating $(\mathrm{Cr} 3 \mathrm{c} 2-25 \mathrm{NiCr})$ produce dense and lamellar structure of coating. The coating also have low percentage of porosity that is $3 \%$ to help increasing the hardness by creating denser protective layer with small pores. HVOF thermal spray process produce coating with low concentrated oxide stringers and reduce brittleness of the coating that been created.

\section{RECOMMENDATION}

Then in terms of the studies that can be carried out in the future, student can do comparison of microstructural studies between different types of coating for example $\mathrm{Cr} 3 \mathrm{C} 2-\mathrm{NiCr}$ vs A12O3.Student also can do a comparison study using the same coating powder with different type of thermal spray process for example HVOF vs plasma coating. In order to safe time during undergo the project, the sample material and the coating powder need to be prepared and purchased early to ensure it is available. This is to ensure the equipment that needed are available such as for cutting the sample and coat it within the target time. The availability of the machinery need to be booked one month early to avoid any held up on the experiment studies. This is because the university equipment often been used for other experiment studies in the university and the quantity of the equipment itself is limited. 


\section{ACKNOWLEDGEMENT}

The author would like to thank Mr David Chue from MetaTech Sdn. Bhd. Malaysia, for his helps in providing the HVOF coating services.

\section{REFERENCES}

[1] Frank J. Hermanek (2001). Thermal Spray Terminology and Company Origins, First Printing.ASM International, Materials Park, $\mathrm{OH}$.

[2] W. E. Ballard (1963). Metal Spraying and the Flame Deposition of Ceramics and Plastics, Fourth Revised Edition.Charles Griffin and Company Limited.London, England.

[3] Davis, J. R. (2004). Thermal Spray Processes. In Handbook of Thermal Spray Technology (pp. 54-76). Ohio: ASM International.

[4] Kim, H.G., Ohmori, A., \& Kim, Y.S. (2004). Study o the properties of $\mathrm{WC}-\mathrm{NiCr}$ and $\mathrm{Cr} 3 \mathrm{C} 2-\mathrm{NiCr}$ cermet coating using the continuous detonation spray method. Proceedings of the International Thermal Spray Conference, $546-550$.

[5] Murthy, J.K.N. \& Venkataraman, B. (2006). Abrasive wear behaviour of $\mathrm{WC}-\mathrm{CoCr}$ and $\mathrm{Cr} 3 \mathrm{C} 2-20(\mathrm{NiCr})$ deposited by HVOF and detonation spray processes. Surface and Coatings Technology (200), 2642 - 2652.

[6] Kamal, S., Jayaganthan, R., \& Prakash, S. (2010). Mechanical and microstructural characteristics of detonation gun sprayed $\mathrm{NiCrAl}+0.4 \mathrm{wt} \% \mathrm{CeO} 2$ coatings on superalloys. Materials Chemistry and Physics (122),
$262-268$.

[7] Kim, H. G., Ohmori, A., \& Kim, Y. S. (2004). Study on the properties of $\mathrm{WC}-\mathrm{NiCr}$ and $\mathrm{Cr} 3 \mathrm{C} 2-\mathrm{NiCr}$ cermet coating using the continuous detonation spray method. Proceedings of the International Thermal Spray Conference, $546-550$.

[8] Zhang, Z., Wang, Z., \& Liang, B. (2009). Wear characterization of thermal spray welded Ni-Cr-B-Si-RE alloy coatings. Journal of Materials Processing Technology (209), $1368-1374$.

[9] Guilemany, J.M., Miguel, J.M., Armada, S., Vizcaino, S., \& Climent, F. (2001). Use of scanning white light interferometry in the characterization of wear mechanisms in thermal-sprayed coatings. Materials Characerization (47), $307-314$.

\section{AUTHOR PROFILE}

Dr. Chennupati Vijayakumar working as principal for sai Spurthi Institute of Technology since 2008 september. He published no ' 10 ' manuscripts in mechanical engineering. Currently his research interest in Welding Technology and Tool design Engineering.

Dr.Subhash kamal , Associate professor, Universiti Teknologi PETRONAS - Department of Mechanical Engineering. He published no ' 20 ' manuscripts in various international Publications. He is expertise in super alloys, Microstructure, EDAX, material Processing, and characterization. 